\title{
GORRESPONDENCE
}

\section{TRAUMATIC ANTERIOR DISLOCATION OF THE HIP}

\author{
From Mr St J. D. Buxton, London, England
}

To the Editor of the Journal of Bone and Joint Surgery.

Sir,

In many numbers of the Journal you publish brief reports of rare and interesting conditions. This practice is to be commended because it draws attention to such rarities and leads to scientific thought and discussion. The report by R. S. Henderson (Journal of Bone and Joint Surgery, $33-B, 602,1951)$ is noteworthy for several reasons and I venture to make comment and amplify his contribution in the hope that assistance may be given to those confronted with a traumatic anterior dislocation of the hip. It is not that my experience exceeds his own, for I can remember only one such case, which was reported for me by E. J. Smith (Proceedings of the Royal Society of Medicine, 27, 579, 1933-34); but the literature is so interesting that it is hoped that your readers will spare some hours in referring to the writings of Astley Cooper (A Treatise on dislocations and fractures of the Joints, 1842, a new edition edited by Bransby B. Cooper. London: John Churchill) whose experience of hip dislocations should be the envy of any surgeon.

Mr Henderson does not seem to know of Astley Cooper's reports in the first half of the last century; for instance, in his article it is stated that forward dislocation is very unusual. In 1842 it was recorded that in twenty cases the relative proportion was: twelve on the dorsum ilii; five in the ischiathic notch; two in the foramen ovale; and one on the pubes. Although three cases of unreduced anterior dislocation were reported there was no mention of failure of reduction within twenty-four hours-which concurs with Henderson's observation. He is surprised to find no record of this lesion being produced by such a simple mechanism as that of his unfortunate football player; but it is interesting to read: "Cause-It happens when a person while walking puts his foot into some unexpected hollow in the ground; and his body at the moment being bent backwards, the head of the bone is thrown forwards upon the os pubis. A gentleman who had met with this dislocation in his own person, informed me that it happened while he was walking across a paved yard in the dark; he did not know that one of the stones had been taken up, and his foot suddenly sank into the hollow, and he fell backwards. When his limb was examined, the head of the thigh bone was found upon the os pubis." The woodcut depicting the deformity shows the right lower limb in lateral rotation and slight abduction as reported by your author.

It would have been of interest to some readers, and of great value to many surgeons in training, if there had been a description of the "attempts to reduce the dislocation by manipulation." Astley Cooper's description of the manipulation is worthy of study, even if no orthopaedic surgeon to-day uses the perineal girth and the thigh pulley.

Yours very truly,

March 24, 1952.

St J. D. BUXTON.

TROCHANTERIC FRAGTURES OF THE FEMUR

Mr Mervyn Evans writes in reply to a letter of Mr J. C. Scott's published in the May issue of the Journal pointing out that $\mathrm{Mr}$ Scott has confused his two series of cases. Only in the first series treated before 1948 and reported in the Journal (Vol. 31-B, 190, 1949) was there selection of cases accounting for the low average age and low mortality. Patients with trochanteric fractures of the femur treated since 1948, and reported in Mr Evans' second article (Vol. 33-B, 192, 1951), were not selected. No patient with a trochanteric fracture of the femur brought to the door of the hospital was turned away, and every one was operated on, the old and the feeble as well as the young. This was in fact a consecutive and entirely unselected series. 